\title{
Anti-coreceptor therapy drives selective $T$ cell egress by suppressing inflammation-dependent chemotactic cues
}

\author{
Aaron J. Martin, ${ }^{1,2}$ Matthew Clark, ${ }^{1}$ Gregory Gojanovich, ${ }^{1}$ Fatima Manzoor, ${ }^{1}$ Keith Miller, ${ }^{1,3}$ \\ Douglas E. Kline, ${ }^{1,4}$ Y. Maurice Morillon, ${ }^{1,5}$ Bo Wang, ${ }^{1}$ and Roland Tisch ${ }^{1,6}$ \\ 'Department of Microbiology and Immunology, University of North Carolina at Chapel Hill School of Medicine, Chapel Hill, \\ North Carolina, USA. ${ }^{2}$ Precision BioSciences, Durham, North Carolina, USA. ${ }^{3}$ Department of Chemistry and Biochemistry, \\ University of Mount Union, Alliance, Ohio, USA. ${ }^{4}$ Committee on Immunology and Department of Medicine, Section of \\ Hematology/Oncology, University of Chicago, Chicago, Illinois, USA. 5Laboratory of Tumor Immunology and Biology, \\ National Cancer Institute, Bethesda, Maryland, USA. 'Lineberger Comprehensive Cancer Center, University of North \\ Carolina at Chapel Hill School of Medicine, Chapel Hill, North Carolina, USA.
}

There continues to be a need for immunotherapies to treat type 1 diabetes in the clinic. We previously reported that nondepleting anti-CD4 and -CD8 Ab treatment effectively reverses diabetes in new-onset NOD mice. A key feature of the induction of remission is the egress of the majority of islet-resident T cells. How this occurs is undefined. Herein, the effects of coreceptor therapy on islet $T$ cell retention were investigated. Bivalent Ab binding to CD4 and CD8 blocked TCR signaling and T cell cytokine production, while indirectly downregulating islet chemokine expression. These processes were required for T cell retention, as ectopic IFN- $\gamma$ or CXCL10 inhibited Ab-mediated T cell purging. Importantly, treatment of humanized mice with nondepleting anti-human CD4 and CD8 Ab similarly reduced tissue-infiltrating human CD4+ and CD8 ${ }^{+} \mathrm{T}$ cells. These findings demonstrate that Ab binding of CD4 and CD8 interrupts a feed-forward circuit by suppressing $T$ cell-produced cytokines needed for expression of chemotactic cues, leading to rapid $\mathrm{T}$ cell egress from the islets. Coreceptor therapy therefore offers a robust approach to suppress $\mathrm{T}$ cell-mediated pathology by purging $\mathrm{T}$ cells in an inflammation-dependent manner.

Authorship note: M. Clark and G. Gojanovich contributed equally to this work.

Conflict of interest: The authors have declared that no conflict of interest exists.

Submitted: March 21, 2016 Accepted: September 13, 2016 Published: October 20, 2016

Reference information: JCI Insight. 2016;1(17):e87636 doi:10.1172/ji.insight.87636.

\section{Introduction}

Clinical onset of type 1 diabetes (T1D) is preceded by infiltration of the pancreatic islets by $\mathrm{CD}^{+}$and $\mathrm{CD}^{+} \mathrm{T}$ cells and other immune effectors, which target the insulin-producing $\beta$ cells (1-3). In NOD mice, a spontaneous model of T1D, insulitis is initiated by an invasion of antigen-presenting cells (APCs) such as macrophages and dendritic cells (DCs) (4-6). Islet APCs deliver acquired autoantigens to the draining pancreatic lymph nodes (PLNs) and stimulate $\beta$ cell-specific T cells, which enter the circulation and migrate to the islets (7). T cells then attack $\beta$ cells in 2 ways: (a) directly, by contact-mediated killing or secretion of cytotoxic cytokines such as IFN- $\gamma$, TNF- $\alpha$, and IL- $1 \beta$, and (b) indirectly, by enhancing the pathogenicity of other islet-resident immune effectors (8-10).

Islet $\mathrm{T}$ cell recruitment is regulated in part by expression of chemokine receptors (CKRs) and corresponding ligands, especially CXCR3 (and CXCL9/10), CCR5 (and CCL3/4/5), and CCR7 (and CCL19/21) (11-14). Once islet T cell residency is established, T cell receptor (TCR) signaling drives expression of proinflammatory cytokines, which further stimulates local production of chemotactic ligands (15-19). T cell-derived IFN- $\gamma$ for instance, upregulates CXCL9 and CXCL10 production by islet-resident cells, including $\beta$ cells, resulting in further recruitment of pathogenic CXCR3 ${ }^{+} \mathrm{T}_{\mathrm{H}} 1$ cells, and innate effectors (20-22). Such feed-forward circuits are thought to be common among autoimmune diseases $(11,15,18)$.

CD4 and CD8 coreceptor molecules play a requisite role in T cell activation following MHC-TCR engagement, and manipulating coreceptor function alters various $\mathrm{T}$ cell processes (23-27). For instance, $\mathrm{Ab}$ binding to coreceptor inhibits TCR signal transduction and induces a hyporesponsive phenotype in naive T cells, whereas CD4 binding by HIV gp120 multimers affects T cell responses to chemotactic cues in vitro 

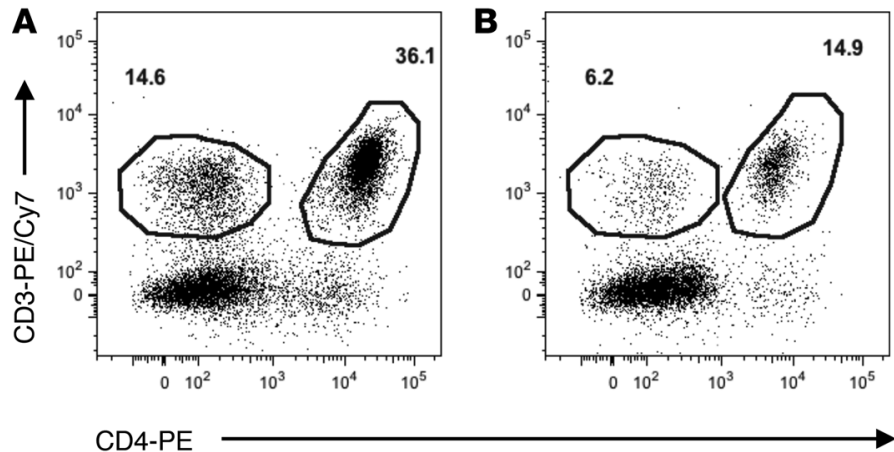

C

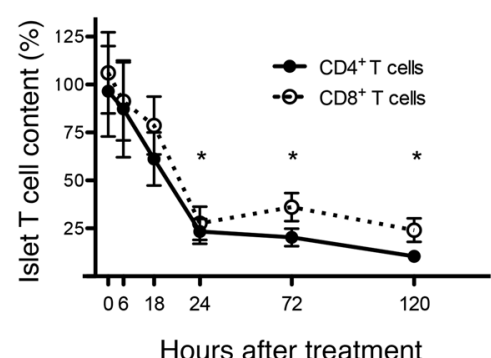

D

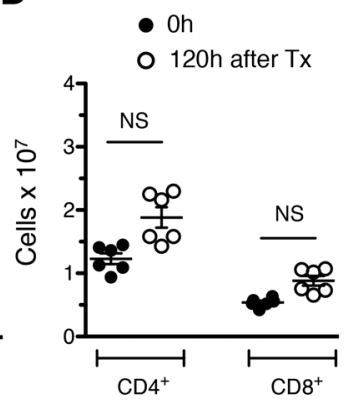

Figure 1. Islet T cell numbers are rapidly reduced by nondepleting YTS Abs. Twelve-week-old NOD female mice received YTS177 and YTS105 or control $2 A 3$. Representative dot plots of islet $C D 4^{+}$and $C D 8^{+}\left(C D 3^{+} C D 4^{-}\right)$T cells in 2A3-treated (A) or YTS-treated mice (B); single live CD45 $5^{+}$events were gated on (outlined in black). Numbers of $C D 4^{+} T$ cells and $C D 8^{+} T$ cells were calculated for islets (C) and spleen (D). ${ }^{*} P<0.01, n=6$, determined by ANOVA with Bonferroni's multiple comparisons correction (C) and two-tailed Student's t test (D). Data represent 3 replicate experiments. NS, not significant; Tx, treatment.

$(28,29)$. The use of nondepleting (ND) Abs specific for CD4 and CD8 has also been effective at inducing allograft- and tissue-specific tolerance in a variety of transplantation and autoimmune models, respectively (28, 30-33). ND anti-CD4 Abs have been used in clinical studies, most recently in NCT0148-1493.

Recently, we reported that ND anti-CD4 (YTS177) and -CD8 (YTS105) Abs rapidly reverse recent-onset diabetes and establish long-term $\beta$ cell-specific tolerance in NOD mice (34). Both YTS Abs are rat IgG2a, and therefore do not lyse target cells in the mouse, owing to weak interactions with murine complement proteins and Fc receptors (30). Induction of remission by coreceptor therapy is accompanied by a robust, nonlytic reduction in $\mathrm{T}$ cell numbers in the pancreas and PLNs, but not in the spleen or peripheral blood. We reasoned that islet $\mathrm{T}$ cell purging could be due to at least 3 mutually nonexclusive scenarios: (a) enhanced $\mathrm{T}$ cell reactivity to egress signals, (b) diminished reactivity to retention cues, and/or (c) loss of retention cues in the islets. In this study, coreceptor crosslinking was found to suppress TCR signaling and T cell cytokine production, which dampened the inflammatory and chemotactic environment, leading to rapid islet $\mathrm{T}$ cell egress. These findings support a model in which islet $\mathrm{T}$ cell retention is dependent on a self-sustaining circuit driven by antigen-stimulated T cells. Furthermore, interfering with this circuit via coreceptor therapy leads to robust therapeutic effects.

\section{Results}

Islet proinflammatory cytokine and chemokine expression is rapidly suppressed by coreceptor therapy. A short course of ND YTS177 (anti-CD4) and YTS105 (anti-CD8 $\alpha$ ) rapidly reverses diabetes in new-onset NOD mice by eliminating $\mathrm{CD}^{+}$and $\mathrm{CD}^{+} \mathrm{T}$ cells in the pancreas and PLNs, but not the spleen, independently of apoptosis (34). This was associated with a decrease in IL-2 and IFN- $\gamma$ protein levels in the pancreas and an asynchronous return (i.e., 2-6 days after treatment) to normal blood glucose levels. To better define the sequence of events regulating $\mathrm{T}$ cell egress by coreceptor therapy, changes in intra-islet $\mathrm{T}$ cell numbers and islet inflammation were assessed over time. Nondiabetic 12-week-old NOD female mice, which exhibit significant islet infiltration $(1,3)$, were examined (Figure 1). Only a minimal reduction in islet $\mathrm{T}$ cell numbers was observed at 6 and 18 hours after YTS, whereas CD4 ${ }^{+}$and $\mathrm{CD} 8^{+} \mathrm{T}$ cells were decreased to $\sim 25 \%$ of control levels at 24 hours and at later posttreatment times (Figure $1 \mathrm{C}$ ). In contrast, a trend towards increased T cells was detected in the spleen 120 hours after treatment (Figure 1D), consistent with previous observations (34).

YTS-induced changes in islet inflammation prior to $\mathrm{T}$ cell purging were examined by measuring cytokine and chemokine mRNA in isolated islets. CD3 mRNA was reduced $\sim 2$ - and 4-fold at 18 and 24 hours after YTS, respectively (Figure 2A), paralleling the rapid decrease in islet T cell numbers (Figure 1C). Expression of IL2, TNFA, and IFNG was significantly reduced by 6 hours in the islets from YTS versus control animals (Figure $2 \mathrm{~B}$ ). IL1B mRNA levels exhibited a distinct temporal profile; expression increased 2-fold at 6 hours, but was reduced $\sim 5$-fold by 18 hours after YTS compared with basal levels (Figure 2B). The rapid downregulation of IFN- $\gamma$ expression suggests that YTS directly suppressed the production of proinflammatory cytokines by $\mathrm{T}$ cells. Indeed, IFNG mRNA was markedly reduced in 

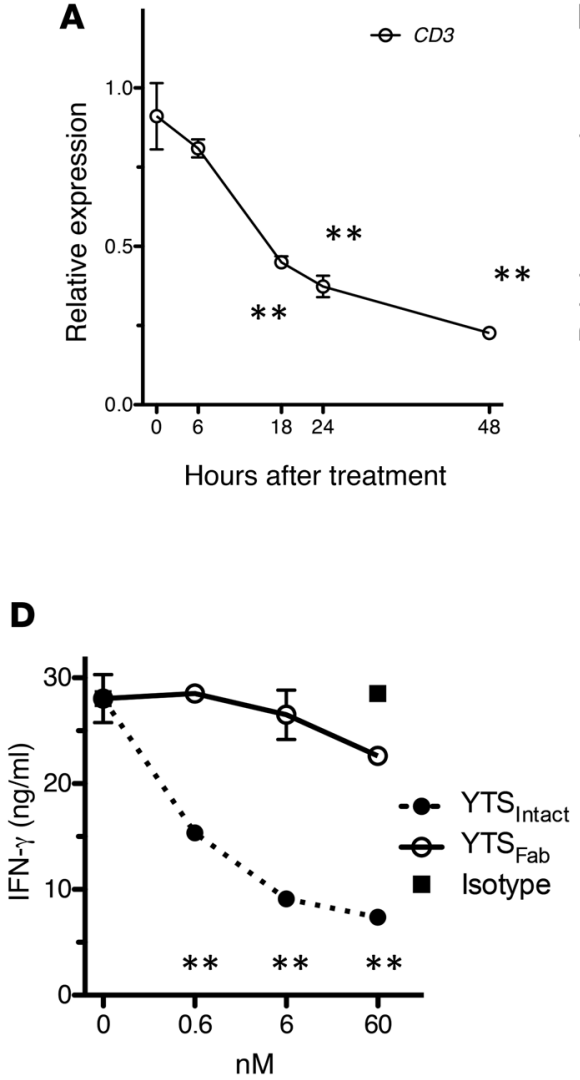

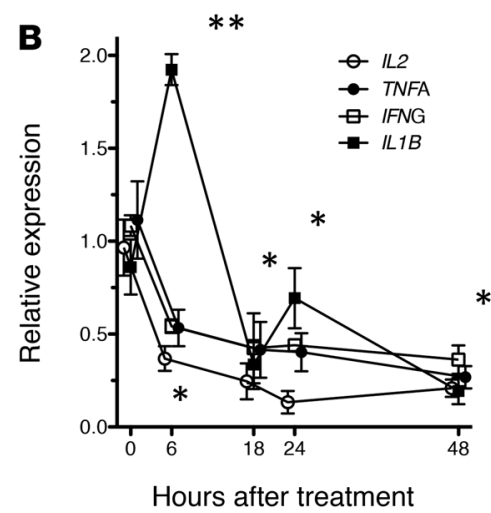

Hours after treatment

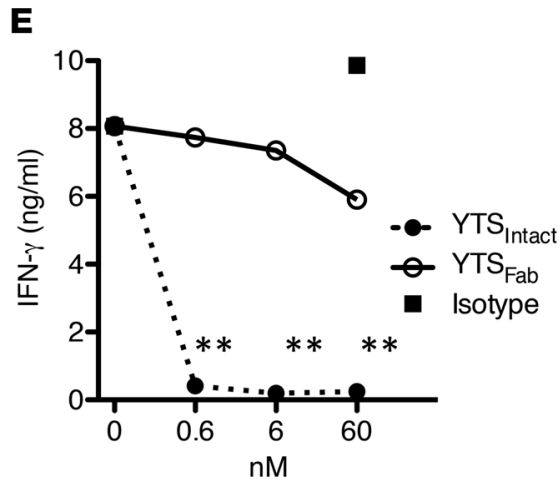

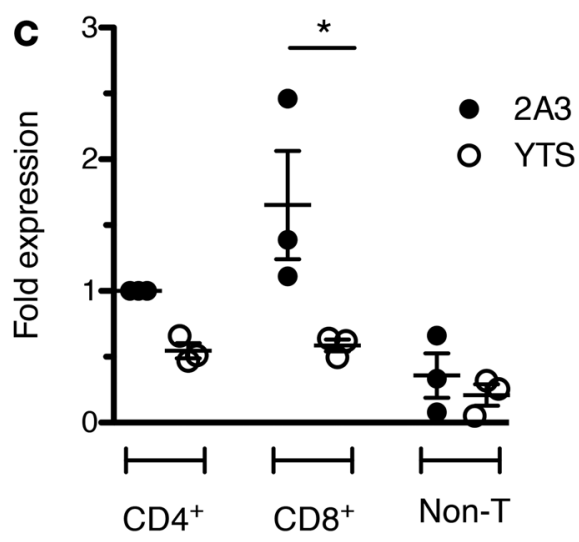

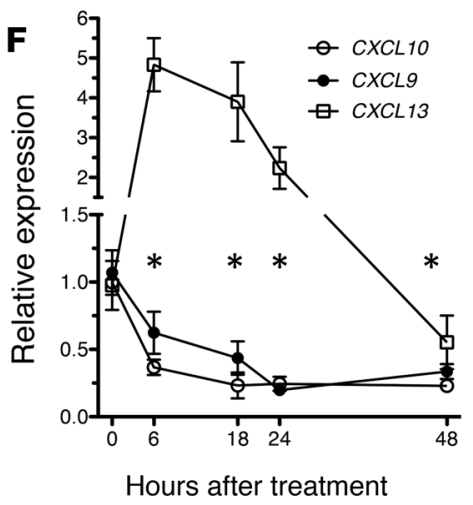

Figure 2. YTS Abs induce rapid reduction of cytokine and chemokine expression in the islets. Twelve-week-old female NOD mice were treated with YTS177 and YTS105 or control 2A3, and RNA prepared from isolated islets pooled from 3 mice at indicated times after treatment. Expression levels of CD3 (A) and proinflammatory cytokines (B). Islets from 3 mice were pooled for each data point. Relative expression data from 3 biological replicates were averaged and plotted. (C) CD4+ and CD8 ${ }^{+}$T cells and non-T cells were sorted from islets harvested 6 hours after treatment and IFNG expression quantified by real-time PCR. Data points indicate 3 biological replicates. Islets were harvested from NOD.BDC (D) or NOD.8.3 (E) mice, cultured for 72 hours with intact or Fab YTS177 or YTS105, respectively, or 2A3, and supernatants assessed for IFN- $\gamma$ via ELISA. Data represent 3 replicate experiments. (F) Expression of CXC-family chemokines was measured by real-time PCR. Islets from 3 mice were pooled for each data point. Relative expression data from 3 biological replicates were averaged and plotted. ${ }^{*} P<0.05,{ }^{*} P<0.01$ (one-way ANOVA and Bonferroni's multiple comparisons correction).

$\mathrm{CD}^{+}$and $\mathrm{CD}^{+} \mathrm{T}$ cells, but not in non-T cells sorted by FACS from islets 6 hours after YTS versus control 2A3-treated mice (Figure 2C). A similar result was obtained in an in vitro assay of IFN- $\gamma$ secretion. Here, islets isolated from NOD.BDC and NOD.8.3 TCR transgenic mice were disaggregated and cultured in the presence of YTS. IFN- $\gamma$ secretion by NOD.BDC CD4 ${ }^{+}$and NOD.8.3 CD8 ${ }^{+}$T cells was suppressed at all concentrations of YTS tested (Figure 2, D and E). YTS Fab monomers (Supplemental Figure 1; supplemental material available online with this article; doi:10.1172/jci.insight.87636DS1) failed to inhibit IFN- $\gamma$ secretion (Figure 2, D and E), indicating that coreceptor blockade per se was insufficient to mediate the suppressive effect of YTS. YTS Fab monomers also failed to reverse T1D and did not induce $\mathrm{T}$ cell egress from the islets in newly diabetic NOD mice (Supplemental Figure 1).

Chemokine gene expression was also reduced in islets from NOD mice after YTS treatment (Figure 2F). IFN- $\gamma$-dependent $C X C L 9$ and $C X C L 10$ expression was significantly decreased as early as 6 hours after treatment and more than 4 -fold by 24 hours after YTS injection (Figure 2D). In contrast, CXCL13 expression, which is inhibited by IFN- $\gamma$, was increased $\sim 5$-fold at 6 hours after YTS and then returned to basal levels. Expression of $C C L 2,3,4,5,19$, and 21 was also reduced within 24 hours following coreceptor therapy (Supplemental Figure 2). These results demonstrate that rapid suppression of $\mathrm{T}$ cell cytokine production, and dampening of the chemotactic milieu of the islets marked by reduced CXCL9 and 10 as well as CC-family chemokine expression, precede coreceptor therapy-induced purging.

$T C R$ signaling is required for islet $T$ cell retention. Antigen stimulation plays a key role in retention of $T$ cells within the islets (15-19). Furthermore, TCR signaling is required for IL2 and IFNG transcription, which is downregulated by YTS $(35,36)$ (Figure 2B). Moreover, Ab binding to CD4 or CD8 typically blocks TCR 

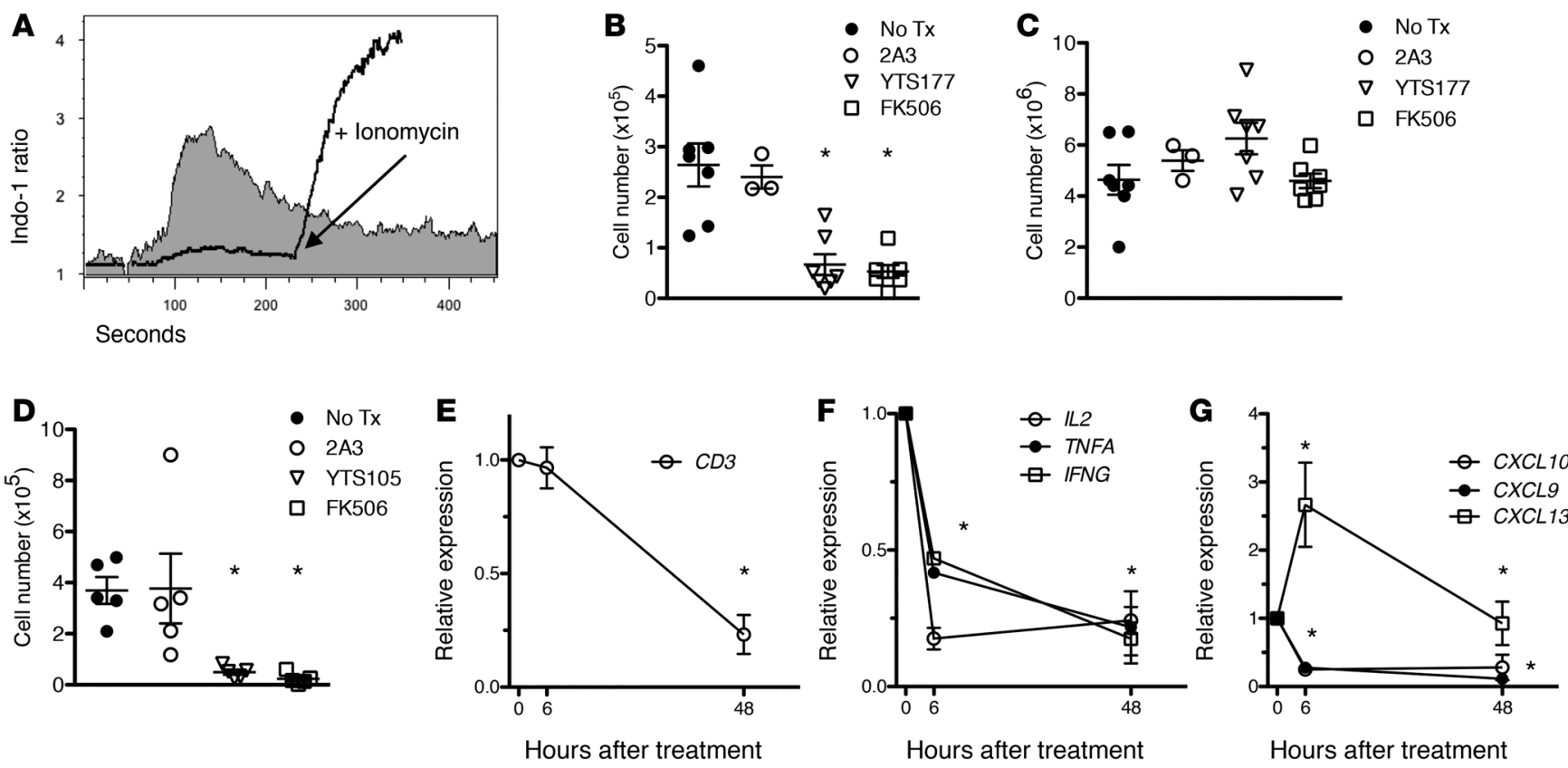

Figure 3. TCR signaling is required for islet T cell retention. (A) Mobilization of intracellular stores of $\mathrm{Ca}^{2+}$ by anti-CD3 Ab was measured in vitro for control T cells (shaded curve) or T cells treated with YTS177 and YTS105 (not shaded). Data represent 3 replicate experiments. YTS-bound T cells were stimulated with ionomycin at 225 seconds. Black line trace shows the ratio of Indo-1 fluorescence in the $\mathrm{Ca}^{2+}$-bound state to that in the $\mathrm{Ca}^{2+}$-unbound state. BDC2.5 female mice were treated with YTS177 $(n=6)$, isotype control Ab $(2 A 3, n=3)$, FK506 $(n=6)$, or left untreated $(n=6)$ and islet (B) and splenic (C) CD4+ T cells enumerated by flow cytometry. (D) NOD.8.3 female mice were treated with YTS105, 2A3, or FK506, and islet CD8 ${ }^{+}$T cells enumerated by flow cytometry $(n=5)$. (E-C) Twelve-week-old NOD female mice were injected with FK506 or PBS ( 0 hours), and mRNA expression in isolated islets measured via qRT-PCR. Islets from 3 mice were pooled for each data point. Data are the average of 3 biological replicates. ${ }^{*} P<0.05$ (one-way ANOVA and Bonferroni's multiple comparisons correction). No Tx, no treatment.

signaling $(28,37)$, suggesting that coreceptor therapy mediates islet $\mathrm{T}$ cell egress by inhibiting TCR signal transduction and downstream effector functions. To initially test this model, the effect of YTS177 and YTS105 on TCR-induced intracellular $\mathrm{Ca}^{2+}$ flux was studied in vitro. Anti-CD3 Ab mobilized intracellular $\mathrm{Ca}^{2+}$ stores in control but not YTS-bound $\mathrm{T}$ cells (Figure 3A). However, $\mathrm{Ca}^{2+}$ flux induced by ionomycin was still detected in YTS-bound T cells (Figure 3A), indicating that blockade of $\mathrm{Ca}^{2+}$ mobilization was due to perturbations to the TCR pathway, and not to cell death or low levels of intracellular calcium following coreceptor ligation.

The outcome of $\mathrm{Ca}^{2+}$ mobilization in $\mathrm{T}$ cells is the activation of calcineurin, which allows nuclear factor of activated T cells (NF-AT) to transactivate early T cell response genes such as IL2 (23). Accordingly, the calcineurin inhibitor FK506 was employed to further assess the relative contribution of TCR signaling in islet $\mathrm{T}$ cell retention. To minimize possible contributions from the highly variable TCR repertoire typical of NOD mice, NOD.BDC2.5 and NOD.8.3 mice were used to measure retention of $\mathrm{CD}^{+}{ }^{+}$and $\mathrm{CD} 8^{+} \mathrm{T}$ effectors, respectively (38). NOD.BDC mice were treated with FK506, and islet T cell egress was compared with the YTS177 and 2A3 treatment groups. Islet CD4+ $\mathrm{T}$ cell numbers were reduced $\sim 5$-fold 6 days after either YTS177 or FK506 treatment (Figure 3B), whereas splenic CD4+ ${ }^{+}$cells were largely unaffected (Figure 3C). FK506 treatment also resulted in reduced $\mathrm{CD} 8^{+} \mathrm{T}$ cells in the islets of NOD.8.3 mice (Figure 3D). Notably, FK506 induced a rapid reduction (e.g., 6 hours) in mRNA expression of IL2, TNFA, and IFNG, as well as CXCL9 and CXCL10, while CXCL13 was upregulated (Figure 3, E and F). Analogously to YTS treatment, these changes occurred prior to T cell egress, as $C D 3$ transcripts were unchanged at 6 hours, but significantly reduced at 48 hours after FK506 treatment (Figure 3G). Together, these findings demonstrate that sustained TCR signaling is necessary for islet T cell retention.

Ectopic IFN- $\gamma$ and CXCL10 prevent islet T cell egress by coreceptor therapy. The above findings suggested a scenario in which coreceptor crosslinking blocked TCR signaling, and directly suppressed $\mathrm{T}$ cell production of proinflammatory cytokines (e.g., IFN- $\gamma$ ), needed for local chemokine production (e.g., CXCL9, CXCL10). To test this model, IFN- $\gamma$ was administered to 12 -week-old NOD female mice, and the effect on YTS-induced islet $\mathrm{T}$ cell purging assessed 24 hours later. As expected, $\mathrm{CD} 4^{+}$and $\mathrm{CD} 8^{+} \mathrm{T}$ 

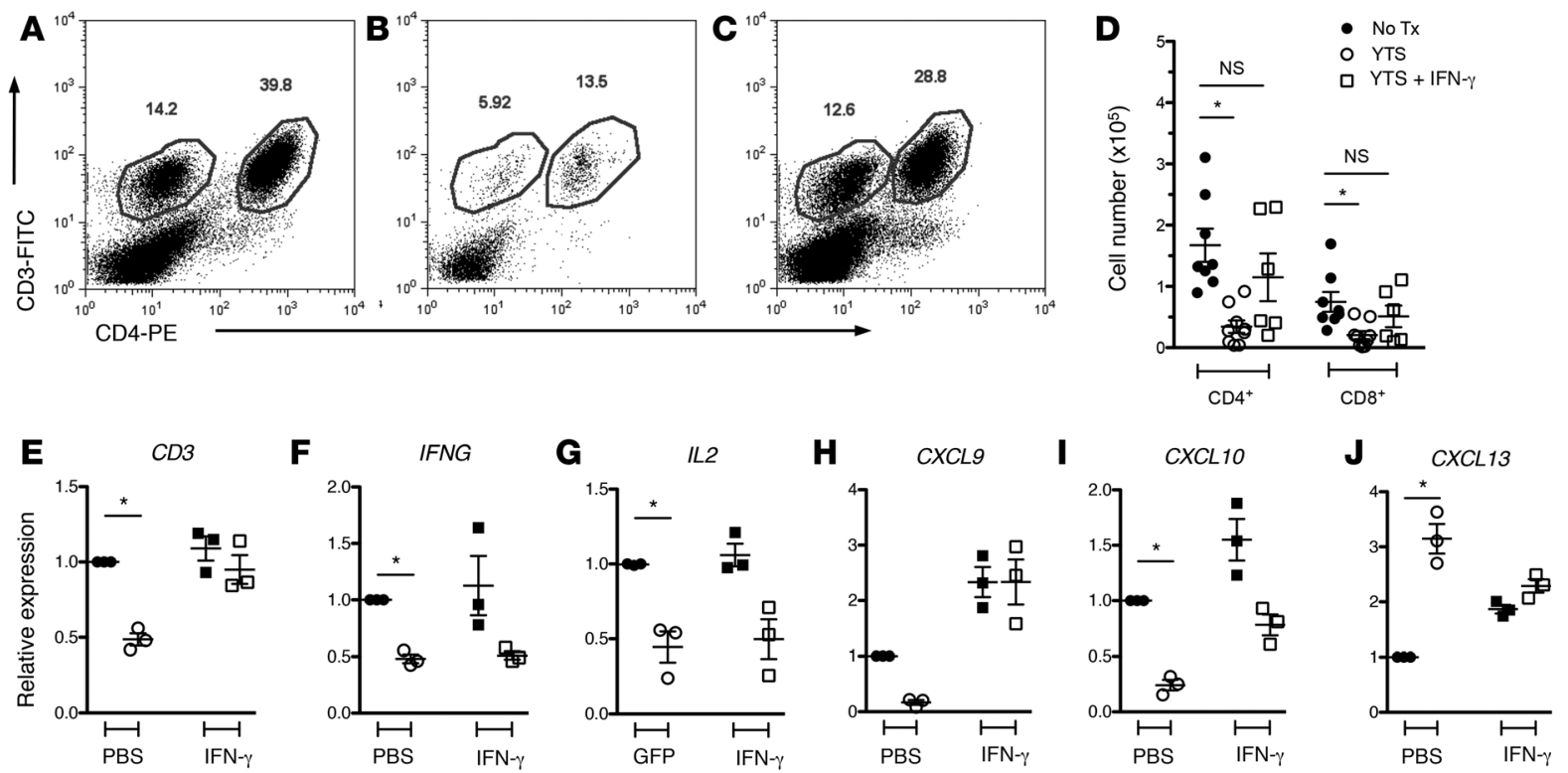

- $\mathrm{GFP}+2 \mathrm{~A} 3$

$0 \mathrm{GFP}+\mathrm{YTS}$

- $\mathrm{IFN}-\gamma+2 \mathrm{~A} 3$

․ IFN- $\gamma+\mathrm{YTS}$
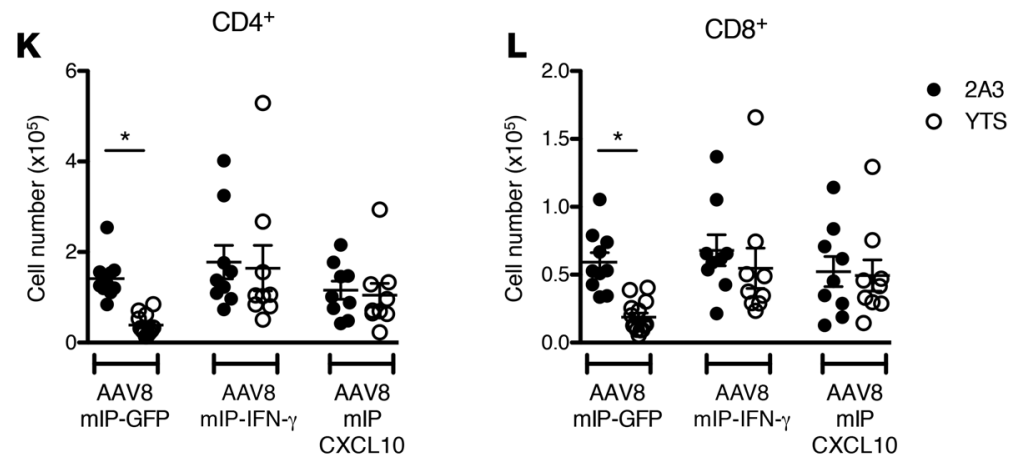

Figure 4. Increased IFN- $\gamma$ and CXCL10 blocks YTS-induced islet T cell purging. (A-F) Twelve-week-old NOD female mice were left untreated (A) or treated with YTS alone (B) or YTS plus rIFN- $\gamma$ (C) and islets harvested 24 hours later. (A-C) Representative dot plots display single live CD45 $5^{+}$events. Blue lines show the gating. (D) Islet T cell numbers for groups of 6 mice. ${ }^{*} P<0.02$. Data represent 3 independent experiments. (E-J) Islet mRNA expression of $C D 3$ (E), IL2 (F), IFNG (C), CXCL9 (H), CXCL10 (I), and CXCL13 (J) was measured via real-time PCR. Islets from 3 mice were pooled for each group. Results are the average of 3 biological replicates. ${ }^{*} P<0.05$, ${ }^{*} P<0.01$. Islet $C D 4^{+}(\mathbf{K})$ and $C D 8^{+}(\mathbf{L})$ T cell numbers from AAVmIP vector-vaccinated NOD mice treated with $\mathrm{YTS}$ or $2 \mathrm{A3}$. Data are the average of 3 independent experiments. ${ }^{*} P<0.05, n=9$. All $P$ values were calculated using one way ANOVA and Bonferroni's multiple comparisons correction. NS, not significant; No Tx, no treatment.

cell numbers were reduced more than 4-fold in the islets of NOD mice receiving YTS alone (Figure 4, B and $\mathrm{D}$ ). In contrast, recombinant ( $\mathrm{r}$ ) IFN- $\gamma$ cotreatment limited YTS-induced purging of islet T cells to less than 2-fold (Figure 4, C and D). Furthermore, NOD mice coinjected with rIFN- $\gamma$ and YTS demonstrated elevated levels of $C D 3, C X C L 9$, and $C X C L 10$ transcripts relative to YTS-only treated animals (Figure 4, E-J). Notably, a comparable decrease in islet IFNG and IL2 mRNA expression was seen in groups receiving either rIFN- $\gamma$ plus YTS or YTS alone, indicating that rIFN- $\gamma$ had no impact on direct T cell suppression by YTS (Figure 4, E-G)

Next, whether islet $\mathrm{T}$ cell egress was due to suppressed chemotactic cues was examined. Here, adeno-associated virus (AAV) vectors encoding CXCL10 (AAV8mIP-CXCL10), IFNG (AAV8mIP-IFN- $\gamma$ ), or GFP (AAV8mIP-GFP) were used. Vectors were packaged with serotype 8 capsid protein for efficient $\beta$ cell transduction in vivo, and $\beta$ cell-specific transgene expression achieved with a mouse insulin promoter (mIP) (39). Twelve-week-old NOD female mice were injected i.p. with $2 \times 10^{10}$ vector particles of AAV8mIP, treated 10 days later with YTS or $2 \mathrm{~A} 3$, and islets examined 24 hours afterwards. Islet $\mathrm{CD} 4^{+}$and $\mathrm{CD} 8^{+} \mathrm{T}$ cells were readily purged in NOD mice treated with YTS plus control AAV8mIP-GFP vector (Figure 4, K and L). Similar to rIFN- $\gamma$ injection (Figure 4D), no significant islet T cell purging was seen in NOD mice treated with YTS and AAV8mIP-IFN- $\gamma$ (Figure 4, K and L). Notably, YTS-mediated islet T cell purging was also inhibited in NOD mice vaccinated with AAV8mIP-CXCL10 (Figure 4, K and L). These results indicate 


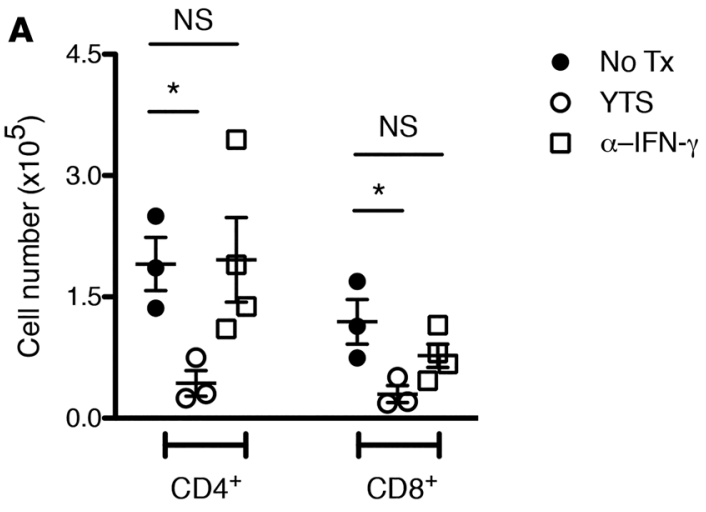

Figure 5. Neutralizing IFN- $\gamma$ alone is insufficient to mediate islet $\mathrm{T}$ cell egress. (A) Groups of 12-week-old NOD female mice were treated with anti-IFN- $\gamma$ Ab $(\alpha-$ IFN- $\gamma)$ or YTS177 and YTS105, islets isolated 48 hours later, and T cells enumerated by flow cytometry. Data represent 2 independent experiments. ${ }^{*} P<$ $0.05, n=3$ (one way ANOVA and Bonferroni's multiple comparisons correction). (B-M) Islets from groups of 3 mice were pooled and gene expression measured via real-time PCR. Data are the average of 3 independent experiments. ${ }^{*} P<$ 0.05 (two-tailed Student's t test). NS, not significant; No Tx, no treatment.
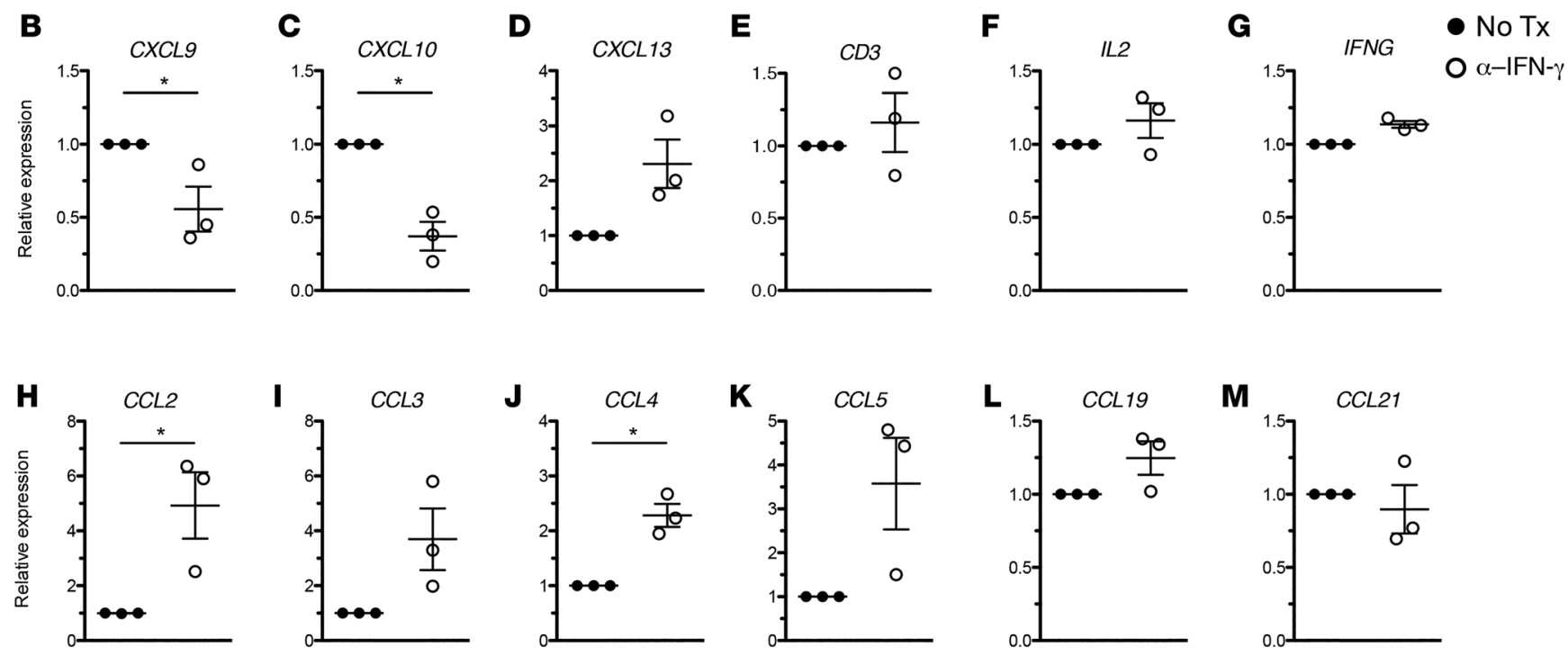

that elevated levels of either islet IFN- $\gamma$ or CXCL10 are sufficient to block YTS-induced T cell egress, and indicate that the downregulation of IFNG and related chemokines is required for YTS-induced T cell egress.

Neutralization of IFN- $\gamma$ alone is insufficient to purge islet T cells. To determine if modulating IFN- $\gamma$ alone is sufficient to drive islet T cell egress, 12-week-old female NOD mice were treated with neutralizing antiIFN- $\gamma \mathrm{Ab}$ and islet $\mathrm{T}$ cell egress was examined. Anti-IFN- $\gamma \mathrm{Ab}$ had only a modest effect on islet $\mathrm{T}$ cell numbers compared with YTS-treated animals (Figure 5A). Anti-IFN- $\gamma$ Ab, however, resulted in a 2- to 3-fold reduction in CXCL9 and CXCL10 mRNA, and an increase in CXCL13 expression, indicative of IFN- $\gamma$ neutralization (Figure 5, B-D). Expression of CD3, IL2 and IFNG was unaffected by anti-IFN-g Ab (Figure 5, E-G). Furthermore, mRNA expression of C-C family chemokines was increased 2- to 6-fold by anti-IFN- $\gamma \mathrm{Ab}$ (Figure 5, H-K).

ND anti-human CD4 and CD8 Ab suppress IFN- $\gamma$ and induce tissue-specific T cell purging in humanized mice. The in vivo effects of coreceptor therapy on human $\mathrm{T}$ cells were investigated. For this purpose, murine CH5g5 (anti-human CD4) and CH9d2 (anti-human CD8 $\alpha$ ) mAbs were established, and the variable segments of the light and heavy chain genes cloned into human $\kappa$ and $\gamma 4$ expression vectors, respectively. The resulting anti-CD4 and anti-CD8 $\alpha$ IgG4 chimeric Abs are nonlytic due to the low complement-activating and Fc-receptor-binding capacities of IgG4 (40). Binding of CH5g5-IgG4 and CH9d2-IgG4 was restricted to $\mathrm{CD}^{+} \mathrm{CD}^{+}$and $\mathrm{CD}^{+} \mathrm{CD}^{+} \mathrm{T}$ cells, respectively (Supplemental Figure 3 ).

NRG mice injected with human peripheral blood mononuclear cells (PBMCs) (NRG-PBL) support engraftment by human $\mathrm{T}$ cells, and develop a $\mathrm{T}$ cell-mediated xenogeneic graft-versus-host disease (xGVHD) manifested in several organs, including the liver and exocrine pancreas (41). Cohorts of NRGPBL mice established with 4 different healthy donors received $1 \mathrm{mg}$ of CH5g5- and CH9d2-IgG4 or were left untreated, and 72 hours later serum levels of human IFN- $\gamma$ and T cell numbers in the pancreas, 
A Serum IFN- $\gamma$

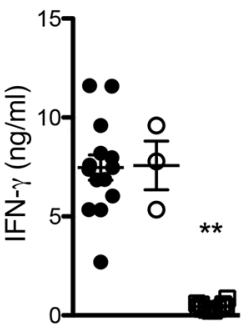

- Control

- Isotype

Combo-treated
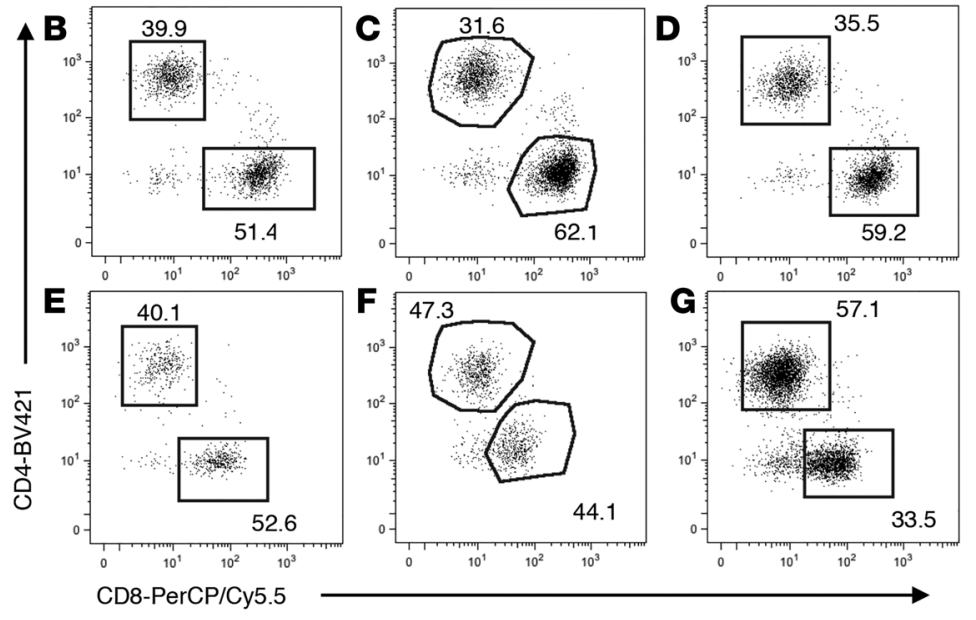

H
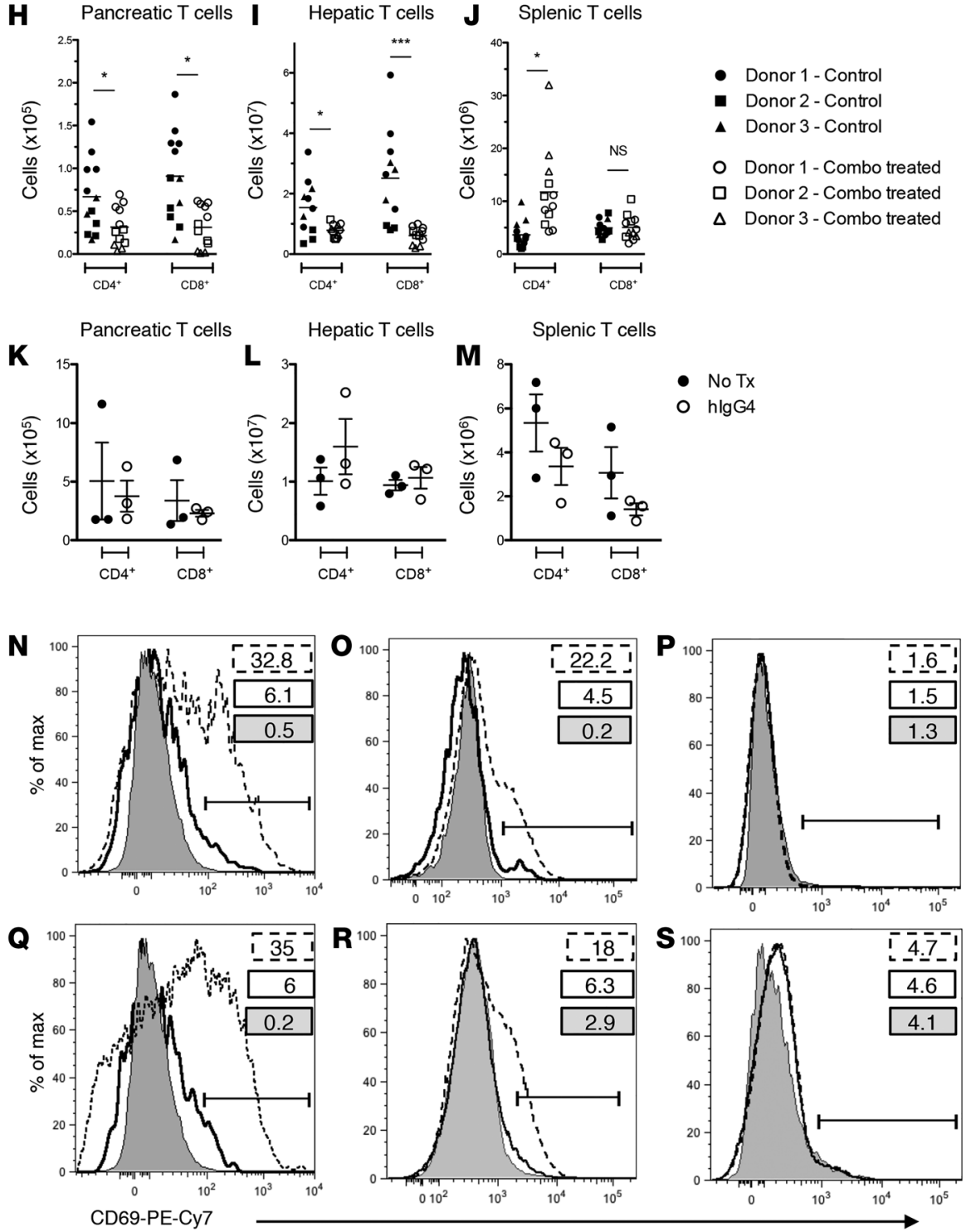

Figure 6. Coreceptor crosslinking suppresses IFN- $\gamma$ and induces selective $\mathrm{T}$ cell tissue purging in peripheral blood mononuclear cell (PBMC)-reconstituted mice. PBMC-reconstituted NOD-Rag ${ }^{-1} / \mathrm{L}-$ $2 \mathrm{Rg}^{-/-}$mice were treated with $1 \mathrm{mg}$ each of $\mathrm{CH} 9 \mathrm{~d} 2$ and $\mathrm{CH} 5 \mathrm{~g} 5$ (combo), $2 \mathrm{mg}$ of human IgG isotype control (isotype), or left untreated (control) (A) Seventy-two hours later, human IFN- $\gamma$ concentration was measured by ELISA in sera of nontreated $(n=12)$, hlgG treated $(n=3)$, and CH9d2+CH5g5-treated mice $(n=$ 12). Human T cells in the control (B-D) and treated (E-G) mice were identified in the pancreas ( $\mathbf{B}$ and $\mathbf{E}$ ), liver (C and $\mathbf{F}$ ), and spleen ( $\mathbf{D}$ and $\mathbf{G}$ ) and were enumerated $(\mathbf{H}-\mathbf{J})(n=12)$ (one way ANOVA and Bonferroni's multiple comparisons correction). The same comparison was made for nontreated versus isotype controltreated mice ( $\mathbf{L}$ and $\mathbf{M}) .{ }^{*} P<0.05$, ${ }^{* *} P<0.01,{ }^{* * *} P<0.001, n=3$. CD69 expression was determined for $\mathrm{CD}^{+}$ $(\mathbf{N}-\mathbf{P})$ and $\mathrm{CD}^{+}(\mathbf{Q}-\mathbf{S}) \mathrm{T}$ cell subsets. CD69 expression is displayed for control (dashed histogram), $\mathrm{CH} 5 \mathrm{~g} 5+\mathrm{CH} 9 \mathrm{~d} 2$-treated mice (solid histogram), and fluorescence minus one (FMO) control (shaded histogram) in the pancreas ( $\mathbf{N}$ and $\mathbf{Q}$ ), liver ( $\mathbf{O}$ and $\mathbf{R}$ ), and spleen ( $\mathbf{P}$ and $\mathbf{S}$ ). Frequency of $\mathrm{CD} \mathrm{9}^{+}$events is listed on each overlay for untreated mice (dashed box) $\mathrm{CH} 9 \mathrm{~d} 2+\mathrm{CH} 5 \mathrm{~g} 5$-treated mice (solid box) and FMO control samples (shaded box). Four different subjects donated PBMCs for these experiments, and results were pooled from all 4 experiments. No Tx, no treatment; NS, not significant.

liver, and spleen were measured (Figure 6, A-M). CH5g5- and CH9d2-IgG4 reduced human IFN- $\gamma$ levels more than 10-fold in the serum of NRG-PBL mice (Figure 6A). In the spleen of CH5g5-IgG4- and CH9d2IgG4-treated NRG-PBL mice, an $\sim 2$-fold increase in $\mathrm{CD}^{+}$ $\mathrm{T}$ cells was detected, whereas splenic $\mathrm{CD}^{+} \mathrm{T}$ cell numbers were unaffected (Figure $6 \mathrm{~J}$ ). In contrast, both pancreatic and hepatic $\mathrm{CD}^{+}$and $\mathrm{CD} 8^{+} \mathrm{T}$ cells

were reduced 2- to 3-fold in CH5g5-IgG4- and CH9d2-IgG4-treated NRG-PBL animals (Figure 6, $\mathrm{H}$ and I). $\mathrm{CD}^{+}$and $\mathrm{CD}^{+} \mathrm{T}$ cell numbers were not significantly affected in the pancreas or liver of NRG-PBL mice injected with control human IgG (Figure 6, K-M). 
The observed $\mathrm{T}$ cell purging induced by $\mathrm{CH} 5 \mathrm{~g} 5$ - and $\mathrm{CH} 9 \mathrm{~d} 2-\mathrm{IgG} 4$ correlated with CD69 expression. Only minimal CD69 expression by $\mathrm{CD}^{+}$and $\mathrm{CD} 8^{+} \mathrm{T}$ cells was observed in the spleens of NRG-PBL mice (Figure 6, $\mathrm{P}$ and S). However, $32.8 \%$ and $35 \%$ of $\mathrm{CD} 4^{+}$and $\mathrm{CD} 8^{+} \mathrm{T}$ cells, respectively, exhibited a CD69hi phenotype in the pancreas of NRG-PBL mice, which was reduced to near baseline levels following CH5g5and $\mathrm{CH} 9 \mathrm{~d} 2-\mathrm{IgG} 4$ treatment (Figure 6, N and Q). Similar results were seen in the liver of NSG-PBL mice (Figure 6, $\mathrm{O}$ and $\mathrm{R}$ ). These results indicate that $\mathrm{Ab}$-mediated coreceptor binding in vivo inhibits TCR signaling in human T cells, resulting in reduced CD69 surface expression and IFN- $\gamma$ secretion, and a selective reduction in tissue-infiltrating human $\mathrm{T}$ effectors.

\section{Discussion}

Targeting CD4 and CD8 with ND Abs has been shown to prevent T cell activation, suppress ongoing effector functions, and induce tolerance in a wide range of models of immune pathology (28, 30-33). The current study demonstrates that YTS-induced islet purging is due to direct suppression of pathogenic T cells, which limits the local inflammatory and chemoattractive milieu needed for tissue retention. Defining these relationships advances our understanding of how ND anti-coreceptor Abs mediate a therapeutic effect in vivo. Notably, coreceptor therapy was also found to purge tissue-infiltrating human $\mathrm{CD}^{+}$and $\mathrm{CD}^{+} \mathrm{T}$ cells in NRG-PBL mice in an inflammation-dependent manner. Similar in vivo effects suggest that YTS and ND anti-human CD4 and -CD8 $\alpha$ Abs share tolerogenic properties, which in turn may be intrinsic to coreceptor therapy.

YTS reverses diabetes in NOD mice, a stringent model for testing the therapeutic efficacy of an immunotherapy $(34,42)$. Several studies have reported on the tolerogenic properties of YTS177 and YTS105 in NOD mice. Administration of YTS105 blocks progression of insulitis and clinical onset in prediabetic NOD mice either in the context of spontaneous disease or in a T cell transfer model $(43,44)$. Similarly, YTS177 is effective at preventing T1D and resolving insulitis in NOD mice after transfer of either diabetogenic splenocytes or primed BDC CD4 ${ }^{+} \mathrm{T}$ cells $(35,45)$. The latter is associated with downregulation of IL2 and IFNG gene expression. Our findings are consistent with and extend these earlier observations by formally establishing a causal link between YTS-induced suppression of TCR signaling, IFN- $\gamma$ loss, and islet T cell egress. Whereas earlier work has focused on either YTS Abs alone, our studies indicate that therapeutic efficacy is enhanced with both YTS177 and YTS105. For instance, diabetes reversal in NOD mice requires YTS177 and YTS105 cotreatment (34), likely reflecting the high frequency and elevated levels of proinflammatory cytokine secretion by islet $\mathrm{CD}^{+}$and $\mathrm{CD}^{+} \mathrm{T}$ effectors at diabetes onset, which in turn drive $\beta$ cell destruction and aid islet $\mathrm{T}$ cell retention. Similarly, the Cooke group showed that both YTS177 and YTS105 are required to induce diabetes remission in new-onset NOD mice (42). Valency of YTS is another factor influencing therapeutic efficacy. Monovalent YTS Fab failed to suppress IFN- $\gamma$ secretion by CD4 ${ }^{+}$ and $\mathrm{CD} 8^{+} \mathrm{T}$ cells (Figure 2, D and E) or reverse diabetes in NOD mice (Supplemental Figure 1), suggesting that crosslinking is needed and blockade per se of coreceptor is insufficient to mediate therapeutic effects.

Antigen stimulation is known to enhance islet $\mathrm{T}$ cell retention $(16,19)$. Furthermore, suppression of TCR signaling is the most studied outcome of coreceptor ligation by $\mathrm{Ab}$. Ab binding to CD4 or CD8 blocks activation of $\mathrm{p} 56^{\mathrm{lck}}$, resulting in hypophosphorylation of TCR signaling intermediates, thereby limiting T cell activation, expansion, and/or effector function $(24-26,46)$. YTS-induced purging of islet $\mathrm{T}$ cells is consistent with these observations. Direct inhibition of TCR signaling was evident by reduced intracellular $\mathrm{Ca}^{2+}$ flux in YTS-bound $\mathrm{T}$ cells (Figure 3A). The importance of ongoing TCR signaling for islet $\mathrm{T}$ cell retention was further seen in NOD mice treated with the calcineurin inhibitor FK506 (Figure 3). FK506 suppressed islet inflammation and induced $\mathrm{T}$ cell purging with rapid kinetics that were strikingly similar to YTS treatment (Figure 3). Calcineurin inhibitors have been shown to reduce insulitis and prevent T1D in NOD mice, while cyclosporin A induces remission in recently diagnosed human T1D patients, albeit with severe complications (47-49). FK506, as well as YTS, blocks IL2 expression (Figures 2B and 3E), which may impact YTS-induced islet T cell purging. $\beta$ cell-specific IL2, however, failed to prevent YTS-induced islet $\mathrm{T}$ cell egress (Supplemental Figure 4). These findings indicate that interrupted TCR signaling is critical for driving ND anti-CD4/CD8 Ab-mediated reversal of insulitis and T1D, and IL-2 is unable to overcome the suppressive effect.

Another key event promoting islet purging by YTS was direct suppression of IFN- $\gamma$ secretion by CD4 ${ }^{+}$ and $\mathrm{CD}^{+} \mathrm{T}$ cells (Figure 2). IFN- $\gamma$ plays an important role in establishing insulitis and maintaining diabetogenic activity of the islet infiltrate by in part regulating the production of recruitment/retention cues, such 
as adhesion molecules and chemokines by islet resident cells (50). Indeed, suppression of IFN- $\gamma$ by YTS resulted in decreased expression of chemokines, including IFN- $\gamma$-regulated CXCL9 and 10 (Figure 2F). On the other hand, injection of rIFN- $\gamma$ or $\beta$ cell-specific IFNG expression effectively blocked YTS-induced islet $\mathrm{T}$ cell purging while maintaining islet chemokine expression (Figure 4). IFN- $\gamma$ neutralization, however, marked by reduced CXCL9 and 10 (Figure 5, B and C) and increased CXCL13 (Figure 5D) was insufficient to reverse established insulitis (Figure 5A). Anti-IFN- $\gamma \mathrm{Ab}$ has been reported to be similarly ineffective in NOD mice once islet T cell residency is established (51). Lack of an effect on insulitis by anti-IFN- $\gamma$ Ab is likely due to a compensatory increase in the expression of $\mathrm{T}_{\mathrm{H}} 1$ chemokines not directly regulated by IFN- $\gamma$, such as CCL2, 3, 4, and 5 (Figure 5, H-K). Additional pathways that stimulate IFN- $\gamma$ secretion by T cells may limit the effects of YTS and therapeutic efficacy. However, YTS continued to suppress IFN- $\gamma$ secretion in disaggregated NOD.BDC islet cultures supplemented with either IL-12 or anti-CD28 Ab (Supplemental Figure 5, A and B). Together, these results support a model in which YTS mediates islet purging by directly suppressing IFN- $\gamma$ production by T cells, which in turn is needed to drive local chemokine levels.

A role for chemokines regulating YTS-induced T cell egress was directly established via AAV8mIP-CXCL10 vaccination. Sustained $\beta$ cell-specific expression of CXCL10 was sufficient to block YTS-induced islet $\mathrm{T}$ cell purging (Figure 4, $\mathrm{K}$ and $\mathrm{L}$ ). Two key conclusions can be drawn from this result. First, CXCL10 not only regulates $\mathrm{T}$ cell migration into the islets $(12-14,20,52)$ but also contributes to retention of pathogenic islet T cells. Second, purging is not due to suppression of CKR function since YTS-bound islet T cells continued to respond to ectopic CXCL10. The reduced inflammatory milieu observed following YTS treatment is also expected to limit trafficking of $\mathrm{T}$ cells into the islets. Indeed, islets of YTS-treated NOD mice remain free of insulitis long term (34). Interestingly, islet DC, macrophage, and B cell numbers were also altered following YTS (Supplemental Figure 6), indicating that other cell types are influenced by the T cell-driven inflammatory milieu in the islets.

Importantly, the in vivo effects of engineered anti-human CD4 and -CD8 $\alpha$ IgG4 on human T cells mimicked observations made for YTS in NOD mice. The chimeric IgG4 was nondepleting; the number of splenic human $\mathrm{CD}^{+} \mathrm{T}$ cells was unperturbed, whereas $\mathrm{CD} 4^{+} \mathrm{T}$ cell numbers were in fact increased in CH5g5-IgG4- and CH9d2-IgG4-treated NRG-PBL mice (Figure 6J). On the other hand, numbers of CD4 ${ }^{+}$ and $\mathrm{CD} 8^{+} \mathrm{T}$ cells in the exocrine pancreas and liver were significantly reduced by CH5g5- and CH9d2-IgG4 treatment (Figure 6, H and I). This tissue purging was independent of the donor used to establish the NRG-PBL mice (Figure 6, H-J). The selectivity of tissue purging may reflect ongoing antigen stimulation of T cells, consistent with the effects of YTS in NOD mice. For instance, the frequency of CD69+ $\mathrm{T}$ cells, indicative of recent antigenic stimulation, was increased 5- to 10-fold in the exocrine pancreas and liver relative to the spleen (Figure 6, N-S). Furthermore, $\mathrm{CH} 5 \mathrm{~g} 5$ - and $\mathrm{CH} 9 \mathrm{~d} 2-\mathrm{IgG} 4$ treatment reduced by more than 5-fold the number of pancreatic and hepatic $\mathrm{CD} 69^{+} \mathrm{T}$ cells (Figure 6, N-S). Also, similarly to YTS, $\mathrm{CH} 5 \mathrm{~g} 5$ - and $\mathrm{CH} 9 \mathrm{~d} 2-\mathrm{IgG} 4$ suppressed cytokine production; serum levels of human IFN- $\gamma$ were reduced $\sim 20$-fold by Ab treatment (Figure 6A). Work is ongoing to better define both the direct and indirect effects of $\mathrm{CH} 5 \mathrm{~g} 5$ - and $\mathrm{CH} 9 \mathrm{~d} 2-\mathrm{IgG} 4$ binding on the function and trafficking properties of human $\mathrm{CD} 4^{+}$and $\mathrm{CD} 8^{+}$ $\mathrm{T}$ effectors, respectively.

In summary, these findings provide the mechanistic basis for the robust tissue purging of $\mathrm{T}$ cells induced by coreceptor therapy. Targeting chemokine-CKR axes as an approach to treat human autoimmunity has encountered several problems, due in part to complex interactions between CKR and multiple ligands, poor immunogenicity of CKR, and posttreatment upregulation of targeted chemokines (52-54). Interestingly, the combination of anti-CD3 and anti-CXCL10 Ab therapy has recently been reported to induce a synergistic effect and reversal of diabetes in NOD mice and a transgenic model of T1D (55). Coreceptor therapy, on the other hand, offers an approach to effectively suppress both T cell-mediated inflammation and downstream expression of chemotactic cues needed for tissue retention of pathogenic $\mathrm{T}$ cells, and other immune effectors. Importantly, our findings also indicate that coreceptor therapy may have similar in vivo effects on human $\mathrm{T}$ cells.

\section{Methods}

Mice and treatments. NOD/ShiLtJ, NOD.Cg-Tg(TcraBDC2.5)1Doi Tg(TcrbBDC2.5)2Doi/DoiJ (NOD. BDC), NOD.Cg-Tg(TcraTcrbNY8.3)1Pesa/DvsJ (NOD.8.3), NOD.CB17-Prkdscid/J (NOD.scid), and NOD.Cg-Rag1 $1^{\mathrm{tm} 1 \mathrm{Mom}} \mathrm{I} 12 \mathrm{rg}^{\mathrm{tm} 1 \mathrm{Wj}} / \mathrm{SzJ}$ (NRG) mice were obtained from the Jackson Laboratory, bred and housed under specific pathogen-free conditions. NOD mice were diagnosed with overt diabetes after 2 consecutive blood glucose readings greater than or equal to $250 \mathrm{mg} / \mathrm{dl}$. NOD mice were treated i.p. with $1 \mathrm{mg}$ 
of ND anti-CD4 and anti-CD8 rat IgG2a. Rat IgG2a isotype control 2A3 was purchased from Bio X Cell. NOD mice were treated with: (a) 10,000 units of murine rIFN- $\gamma$ i.v. every 6 hours for the duration of the experiment (Peprotech), (b) $1 \mathrm{mg} / \mathrm{kg}$ of FK506 i.p. every other day (Abcam), and (c) $500 \mu \mathrm{g}$ of anti-IFN- $\gamma$ $\mathrm{Ab}$ (clone R4-6A2) i.p. daily for 2 days. R4-6A2, YTS177, and YTS105 Abs were produced in-house from supernatants of cultured hybridomas, as previously described (56). The R4-6A2 line was purchased from ATCC. YTS177 and YTS105 hybridomas were a gift from Herman Waldmann (University of Oxford).

NRG mice were reconstituted with $15 \times 10^{6}$ to $20 \times 10^{6}$ fresh PBMCs prepared by Ficoll-Paque Plus (GE Healthcare). Human reconstitution of animals was monitored via flow cytometry for human CD45 cells in peripheral blood. Four to 6 weeks after transfer, mice were injected with $1 \mathrm{mg}$ of CH5g5 and $1 \mathrm{mg}$ of $\mathrm{CH} 9 \mathrm{~d} 2$ or $2 \mathrm{mg}$ of polyclonal human IgG (Bio X Cell) via the i.p. route. Seventy-two hours following $\mathrm{Ab}$ injection, mice were sacrificed for analyses of sera and $\mathrm{T}$ cell content of organs.

Flow cytometry and T cell enumeration. Single-cell suspensions were prepared from tissues, and RBCs lysed using Tris-buffered ammonium chloride. Pancreases were perfused with $2 \mathrm{mg} / \mathrm{ml}$ collagenase P (Roche) via the common bile duct and islets isolated on a Lympholyte 1.1 gradient (Cedarlane). Infiltrating leukocytes were liberated from hand-picked islets using an enzyme-free dissociation buffer (Life Technologies) prior to staining. Pacific Orange-succinimidyl ester or blue-reactive LIVE/DEAD discriminator dyes were used to identify viable cells (Life Technologies). The following fluorochrome-conjugated Abs were purchased from eBioscience, Biolegend, or BD Biosciences: anti-CD45-BrilliantViolet-421 (clone 30-F11), anti-CD4-PE (clone RM4-4), anti-

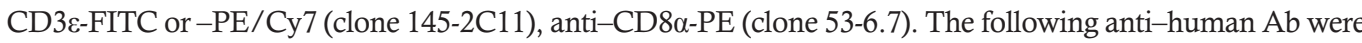
used (all purchased from BD Biosciences): anti-CD45-APC-H7 (clone 2D1), anti-CD3-FITC (clone OKT3), anti-CD4-BV421 (clone OKT4), anti-CD8-PerCP-Cy5.5 (clone SK1), and anti-CD69-PE/Cy7 (clone L78). Anti-human IgG-PE (catalog 2040-09) was purchased from Southern Biotech. T cells were enumerated using AccuCheck counting beads (Life Technologies). Flow cytometric data were acquired using a Becton-Dickinson LSRII or a Beckman-Coulter CyAn ADP, and data analyzed using FlowJo software (Treestar).

Quantitative real-time PCR. RNA was prepared from isolated islets using RNeasy PLUS columns (QIAGEN), and cDNA synthesized using SuperScript III (Life Technologies) according to the manufacturers' recommendations. cDNA (50 ng) was amplified via a Maxima SYBR green master mix (Thermo Fisher Scientific) and an ABI Prism 7500 (Applied Biosystems). Ct values were calculated by the $\Delta \Delta \mathrm{Ct}$ method and ABI Sequence Detection System software, and normalized to HPRT values and calibrated to a control sample.

IFN- $\gamma$ production by intra-islet leukocytes. Isolated islets were disaggregated and cultured in round-bottom 96-well plates at $37^{\circ} \mathrm{C}$ and $5.5 \% \mathrm{CO}_{2}$. Twenty-five (NOD.BDC) or 50 (NOD.8.3) islets were cultured in 200 $\mu 1$ DMEM supplemented with 10\% FBS, L-glutamine, penicillin-streptomycin, and $\beta$-mercaptoethanol. Following 72 hours of culture, IFN- $\gamma$ was measured in supernatants using an OptEIA set (BD Biosciences).

$A A V$ vector production and treatment. Full-length murine IFN- $\gamma$ and CXCL10 cDNAs were cloned into a double-stranded AAV plasmid and expression driven by mIP (39). For packaging, AAVmIP-IFN- $\gamma$ or AAVmIP-CXCL10 plasmids, an adeno helper plasmid (pXX6-80), and serotype capsid 8 encoding plasmid were cotransfected into HEK-293T cells using polyethylenimine. Seventy-two hours after transfection, nuclear fractions were harvested, and vector particles purified by cesium chloride centrifugation. Vector copy number was determined by real-time PCR using the standard curve method. Packaged AAV vector $\left(2 \times 10^{10}\right.$ vector particles $)$ was administered i.p.

Preparation of Fab monomers. Purified YTS177 and YTS105 were digested with papain using a Pierce Fab Preparation Kit (Thermo Fisher Scientific). Fab monomers were purified on an ÄKTA protein purification fast performance liquid chromatography (FPLC) system using a GE Healthcare HiTrap Q Sepharose HP and HiTrap DEAE Sepharose FF column, respectively. Fab monomer purity was confirmed by SDS-PAGE, and binding to CD4 or CD8 measured by flow cytometry using a goat anti-rat AlexaFluor488 conjugate (Life Technologies, catalog A-11006).

Mobilization of intracellular calcium. Lymphocytes were labeled with $2.5 \mu \mathrm{M}$ Indo-1 AM (Life Technologies) in HBSS plus $1 \%$ FBS. Labeling was carried out at $37^{\circ} \mathrm{C}$ for 60 minutes at a cell concentration of $2 \times 10^{6} / \mathrm{ml}$. Cells were washed and treated with $5 \mu \mathrm{g} / \mathrm{ml}$ biotinylated anti-CD $3 \varepsilon(145.2 \mathrm{C} 11$, BioLegend $)$ and titrated amounts of anti-CD19-APC (eBioscience, clone 1D3) on ice. Cells were washed and suspended in HBSS plus $1 \%$ FCS and brought to $37^{\circ} \mathrm{C}$ before flow cytometric analysis. Thirty seconds into the analysis, acquisition was paused, and one volume of $25 \mu \mathrm{g} / \mathrm{ml}$ unlabeled streptavidin added (Life Technologies); acquisition was then restarted. 
ND anti-human CD4 and CD8 . Murine hybridoma lines secreting mouse anti-human CD4 and CD8 $\alpha$ Abs were established using the Ag8.653 fusion partner (purchased from ATCC) according to the method of Kohler and Milstein (56). RNA was harvested from monoclonal hybridoma lines and the variable region genes for heavy and light chains amplified by PCR using Ambion 5' RLM-RACE reagents (Life Technologies), and cloned into a TOPO 2.1-TA vector (Life Technologies) for sequencing. Light chain variable region genes were subcloned into a pFUSE2-CLIg-human $\kappa$ expression vector and heavy chain variable region genes subcloned into a pFUSE2-CHIg-human $\gamma 4$ expression vector (InvivoGen). Expi293 cells were transfected according to the vendor's instructions (Life Technologies) and human IgG4 purified by protein A affinity chromatography (Hi-Trap Protein A, GE Healthcare).

Statistics. Data on scatter and line plots appear with the mean identified by a horizontal line. Error bars represent standard error of the mean (SEM). For experiments containing 2 groups, 2-tailed Student's $t$ test was used to determine significance. For experiments containing more than 2 groups, 1-way analysis of variance (ANOVA) with Bonferroni's multiple comparisons correction was used to determine significance. Differences were considered to be significant when $P<0.05$.

Study approval. All animal procedures were approved by the University of North Carolina at Chapel Hill (UNC-CH) IACUC. Human PBMCs were collected from healthy donors enrolled in the study in accordance with UNC-CH IRB guidelines.

\section{Author contributions}

AJM designed and performed experiments, interpreted results, prepared the manuscript, produced, and evaluated Abs. GG produced viral vectors, provided experimental support, and made intellectual contributions. MC and DEK provided experimental support and made intellectual contributions. KM purified and evaluated Fab fragments. FM provided experimental support and oversaw human PBMC procurement. YMM produced and evaluated Abs and viral vectors and made intellectual contributions. BW reviewed data and made intellectual contributions. RT is the principal investigator and made intellectual contributions, interpreted results, and prepared the manuscript.

\section{Acknowledgments}

This study was supported by funding from the National Institutes of Health (R01 DK100256-02, R21AI115752-01) to R.T., and the Juvenile Diabetes Research Foundation (10-2011-425) to A.J.M. The UNC Flow Cytometry Core Facility is supported in part by P30 CA016086 Cancer Center Core Support Grant to the UNC Lineberger Comprehensive Cancer Center, and North Carolina Biotech Center Institutional Support Grant 2005-IDG-1016. The authors also acknowledge the UNC Antibody Core Facility, under the direction of Michael Miley, as well as Rui Zhang for technical support.

Address correspondence to: Roland Tisch, University of North Carolina at Chapel Hill, Department of Microbiology and Immunology, 6th Floor Marsico Hall Room 6111, Campus Box 7290, 125 Mason Farm Road, Chapel Hill, North Carolina 27599-7290, USA. Phone: 919.966.4766; E-mail: rmtisch@med.unc.edu.

GG's present address is: Center for Cardiovascular Research, University of Hawaii, Honolulu, Hawaii, USA.

1. Tisch R, McDevitt H. Insulin-dependent diabetes mellitus. Cell. 1996;85(3):291-297.

2. Bach JF. Autoimmunity and type I diabetes. Trends Endocrinol Metab. 1997;8(2):71-74.

3. Anderson MS, Bluestone JA. The NOD mouse: a model of immune dysregulation. Annu Rev Immunol. 2005;23:447-485.

4. Dahlén E, Dawe K, Ohlsson L, Hedlund G. Dendritic cells and macrophages are the first and major producers of TNF-alpha in pancreatic islets in the nonobese diabetic mouse. J Immunol. 1998;160(7):3585-3593.

5. Jun HS, Santamaria P, Lim HW, Zhang ML, Yoon JW. Absolute requirement of macrophages for the development and activation of beta-cell cytotoxic CD8+ T-cells in T-cell receptor transgenic NOD mice. Diabetes. 1999;48(1):34-42.

6. Lee KU, Amano K, Yoon JW. Evidence for initial involvement of macrophage in development of insulitis in NOD mice. Diabetes. 1988;37(7):989-991.

7. Gagnerault MC, Luan JJ, Lotton C, Lepault F. Pancreatic lymph nodes are required for priming of beta cell reactive T cells in NOD mice. J Exp Med. 2002;196(3):369-377.

8. Cnop M, Welsh N, Jonas JC, Jörns A, Lenzen S, Eizirik DL. Mechanisms of pancreatic beta-cell death in type 1 and type 2 diabetes: many differences, few similarities. Diabetes. 2005;54 Suppl 2:S97-S107.

9. Yoon JW, Jun HS. Autoimmune destruction of pancreatic beta cells. Am J Ther. 2005;12(6):580-591.

10. Pang S, et al. CD8(+) T cells specific for beta cells encounter their cognate antigens in the islets of NOD mice. Eur J Immunol. 
2009;39(10):2716-2724.

11. Rotondi M, Chiovato L, Romagnani S, Serio M, Romagnani P. Role of chemokines in endocrine autoimmune diseases. Endocr Rev. 2007;28(5):492-520.

12. Sarkar SA, et al. Expression and regulation of chemokines in murine and human type 1 diabetes. Diabetes. 2012;61(2):436-446.

13. Rhode A, et al. Islet-specific expression of CXCL10 causes spontaneous islet infiltration and accelerates diabetes development. J Immunol. 2005;175(6):3516-3524.

14. Tanaka S, et al. Enterovirus infection, CXC chemokine ligand 10 (CXCL10), and CXCR3 circuit: a mechanism of accelerated beta-cell failure in fulminant type 1 diabetes. Diabetes. 2009;58(10):2285-2291.

15. Calderon B, Carrero JA, Miller MJ, Unanue ER. Entry of diabetogenic T cells into islets induces changes that lead to amplification of the cellular response. Proc Natl Acad Sci U S A. 2011;108(4):1567-1572.

16. Calderon B, Carrero JA, Miller MJ, Unanue ER. Cellular and molecular events in the localization of diabetogenic T cells to islets of Langerhans. Proc Natl Acad Sci U S A. 2011;108(4):1561-1566.

17. Calderon B, Suri A, Pan XO, Mills JC, Unanue ER. IFN-gamma-dependent regulatory circuits in immune inflammation highlighted in diabetes. J Immunol. 2008;181(10):6964-6974.

18. Carrero JA, Calderon B, Towfic F, Artyomov MN, Unanue ER. Defining the transcriptional and cellular landscape of type 1 diabetes in the NOD mouse. PLoS One. 2013;8(3):e59701.

19. Lennon GP, et al. T cell islet accumulation in type 1 diabetes is a tightly regulated, cell-autonomous event. Immunity. 2009;31(4):643-653.

20. Frigerio S, et al. Beta cells are responsible for CXCR3-mediated T-cell infiltration in insulitis. Nat Med. 2002;8(12):1414-1420.

21. Lee HH, Farber JM. Localization of the gene for the human MIG cytokine on chromosome 4q21 adjacent to INP10 reveals a chemokine "mini-cluster". Cytogenet Cell Genet. 1996;74(4):255-258.

22. Luster AD, Unkeless JC, Ravetch JV. Gamma-interferon transcriptionally regulates an early-response gene containing homology to platelet proteins. Nature. 1985;315(6021):672-676.

23. Acuto O, Di Bartolo V, Michel F. Tailoring T-cell receptor signals by proximal negative feedback mechanisms. Nat Rev Immunol. 2008;8(9):699-712.

24. Luo KX, Sefton BM. Cross-linking of T-cell surface molecules CD4 and CD8 stimulates phosphorylation of the lck tyrosine protein kinase at the autophosphorylation site. Mol Cell Biol. 1990;10(10):5305-5313.

25. Zuñiga-Pflücker JC, McCarthy SA, Weston M, Longo DL, Singer A, Kruisbeek AM. Role of CD4 in thymocyte selection and maturation. J Exp Med. 1989;169(6):2085-2096.

26. Dianzani U, Shaw A, Fernandez-Cabezudo M, Janeway CA. Extensive CD4 cross-linking inhibits T cell activation by anti-receptor antibody but not by antigen. Int Immunol. 1992;4(9):995-1001.

27. Madrenas J, Chau LA, Smith J, Bluestone JA, Germain RN. The efficiency of CD4 recruitment to ligand-engaged TCR controls the agonist/partial agonist properties of peptide-MHC molecule ligands. J Exp Med. 1997;185(2):219-229.

28. Pullar CE, Morris PJ, Wood KJ. Altered proximal T-cell receptor signalling events in mouse CD4 ${ }^{+} \mathrm{T}$ cells in the presence of antiCD4 monoclonal antibodies: evidence for reduced phosphorylation of Zap-70 and LAT. Scand J Immunol. 2003;57(4):333-341.

29. Green DS, Center DM, Cruikshank WW. Human immunodeficiency virus type 1 gp120 reprogramming of CD4+ T-cell migration provides a mechanism for lymphadenopathy. $J$ Virol. 2009;83(11):5765-5772.

30. Waldmann H, Adams E, Cobbold S. Reprogramming the immune system: co-receptor blockade as a paradigm for harnessing tolerance mechanisms. Immunol Rev. 2008;223:361-370.

31. O'Neill JK, et al. Control of immune-mediated disease of the central nervous system with monoclonal (CD4-specific) antibodies. J Neuroimmunol. 1993;45(1-2):1-14.

32. Duarte $\mathrm{J}$, et al. T cell apoptosis and induction of Foxp $3^{+}$regulatory T cells underlie the therapeutic efficacy of CD4 blockade in experimental autoimmune encephalomyelitis. J Immunol. 2012;189(4):1680-1688.

33. Li L, Crowley M, Nguyen A, Lo D. Ability of a nondepleting anti-CD4 antibody to inhibit Th2 responses and allergic lung inflammation is independent of coreceptor function. J Immunol. 1999;163(12):6557-6566.

34. Yi Z, et al. Long-term remission of diabetes in NOD mice is induced by nondepleting anti-CD4 and anti-CD8 antibodies. Diabetes. 2012;61(11):2871-2880.

35. Phillips JM, Harach SZ, Parish NM, Fehervari Z, Haskins K, Cooke A. Nondepleting anti-CD4 has an immediate action on diabetogenic effector cells, halting their destruction of pancreatic beta cells. J Immunol. 2000;165(4):1949-1955.

36. Chirmule N, Avots A, LakshmiTamma SM, Pahwa S, Serfling E. CD4-mediated signals induce T cell dysfunction in vivo. J Immunol. 1999;163(2):644-649.

37. Fehérvári Z, Cooke A, Brett S, Turner J. Perturbation of naive TCR transgenic T cell functional responses and upstream activation events by anti-CD4 monoclonal antibodies. Eur J Immunol. 2002;32(2):333-340.

38. Ho S, et al. The mechanism of action of cyclosporin A and FK506. Clin Immunol Immunopathol. 1996;80(3 Pt 2):S40-S45.

39. Johnson MC, et al. $\beta$-cell-specific IL-2 therapy increases islet Foxp $3^{+}$Treg and suppresses type 1 diabetes in NOD mice. Diabetes. 2013;62(11):3775-3784.

40. Salfeld JG. Isotype selection in antibody engineering. Nat Biotechnol. 2007;25(12):1369-1372.

41. King MA, et al. Human peripheral blood leucocyte non-obese diabetic-severe combined immunodeficiency interleukin-2 receptor gamma chain gene mouse model of xenogeneic graft-versus-host-like disease and the role of host major histocompatibility complex. Clin Exp Immunol. 2009;157(1):104-118.

42. Phillips JM, et al. Type 1 diabetes development requires both $\mathrm{CD} 4^{+}$and $\mathrm{CD} 8^{+} \mathrm{T}$ cells and can be reversed by non-depleting antibodies targeting both T cell populations. Rev Diabet Stud. 2009;6(2):97-103.

43. Wang B, Gonzalez A, Benoist C, Mathis D. The role of $\mathrm{CD}^{+} \mathrm{T}$ cells in the initiation of insulin-dependent diabetes mellitus. Eur J Immunol. 1996;26(8):1762-1769.

44. Parish NM, Bowie L, Zusman Harach S, Phillips JM, Cooke A. Thymus-dependent monoclonal antibody-induced protection from transferred diabetes. Eur J Immunol. 1998;28(12):4362-4373.

45. Hutchings P, O'Reilly L, Parish NM, Waldmann H, Cooke A. The use of a non-depleting anti-CD4 monoclonal antibody to re-establish tolerance to beta cells in NOD mice. Eur J Immunol. 1992;22(7):1913-1918. 
46. Haque S, Saizawa K, Rojo J, Janeway CA. The influence of valence on the functional activities of monoclonal anti-L3T4 antibodies. Discrimination of signaling from other effects. J Immunol. 1987;139(10):3207-3212.

47. Sobel DO, Henzke A, Abbassi V. Cyclosporin and methotrexate therapy induces remission in type 1 diabetes mellitus. Acta Diabetol. 2010;47(3):243-250.

48. Stiller CR, et al. Effects of cyclosporine immunosuppression in insulin-dependent diabetes mellitus of recent onset. Science. 1984;223(4643):1362-1367.

49. Assan R, et al. Metabolic and immunological effects of cyclosporin in recently diagnosed type 1 diabetes mellitus. Lancet. 1985;1(8420):67-71.

50. Savinov AY, Wong FS, Chervonsky AV. IFN-gamma affects homing of diabetogenic T cells. J Immunol. 2001;167(11):6637-6643.

51. Debray-Sachs M, et al. Prevention of diabetes in NOD mice treated with antibody to murine IFN gamma. J Autoimmun. $1991 ; 4(2): 237-248$.

52. Coppieters KT, et al. Functional redundancy of CXCR3/CXCL10 signaling in the recruitment of diabetogenic cytotoxic T lymphocytes to pancreatic islets in a virally induced autoimmune diabetes model. Diabetes. 2013;62(7):2492-2499.

53. Targeting chemokines chemokine receptors with antibodies. Drug Discov Today Technol. 2012;9(4):e227-e314.

54. Hutchings CJ, Koglin M, Marshall FH. Therapeutic antibodies directed at G protein-coupled receptors. MAbs. 2010;2(6):594-606.

55. Lasch S, et al. Anti-CD3/anti-CXCL10 antibody combination therapy induces a persistent remission of type 1 diabetes in two mouse models. Diabetes. 2015;64(12):4198-4211.

56. Yokoyama WM, et al. Production of monoclonal antibodies. Curr Protoc Immunol. 2013;102:Unit 2.5 